\title{
USO DA GEOTECNOLOGIA PARA CARACTERIZAR OS CAFEZAIS NO MUNICÍPIO DE LONDRINA-PR, EM RELAÇÃO À ALTIMETRIA, DECLIVIDADE E TIPO DE SOLO
}

\author{
KLEBER TRABAQUINI ${ }^{1}$, ÉDISON MIGLIORANZA ${ }^{2}$, VALMIR DE FRANÇA ${ }^{3}$, \\ OSVALDO C. PEREIRA NETO ${ }^{4}$
}

\begin{abstract}
RESUMO: O sensoriamento remoto e o geoprocessamento são ferramentas importantes no apoio aos levantamentos de dados da agricultura. O estudo teve por objetivo relacionar as variáveis físicas, como altimetria, declividade e tipo de solo com o agrossistema cafeeiro, no município de Londrina-PR, por meio de imagem do sensor Thematic Mapper (TM) do satélite Landsat-5, aliado às técnicas de geoprocessamento. Foi criado um banco de dados com informações de altimetria, declividade e classes de solos, e através de álgebra de mapa, realizado o cruzamento destas informações com a localização das lavouras cafeeiras, a qual foi obtida por meio do classificador digital Bhattacharya aplicado na imagem. A imagem do TM possibilitou o mapeamento de $79 \%$ das lavouras cafeeiras e verificou-se que $86 \%$ destas lavouras estão em altitudes superiores a $540 \mathrm{~m}$, e $50 \%$ estão localizadas sobre áreas de 8 a $20 \%$ de declividade. Em relação aos solos, observou-se que 53\% dos cafeeiros estão localizados em Nitossolo Vermelho eutroférrico. Todas estas tarefas foram executadas por meio do programa SPRING 4.3.3, o qual foi uma adequada ferramenta para obter dados da agricultura a partir de imagens de satélites.
\end{abstract}

PALAVRAS-CHAVE: café, geomática, caracterização ambiental.

\section{THE USE OF GEOTECHNOLOGY TO CHARACTERIZE COFFEE CROPS IN LONDRINA-PR, FOR ALTIMETRY, SLOPE AND SOIL TYPE}

\begin{abstract}
The remote sensing and geoprocessing are important tools in supporting the data collecting in agriculture. This study aimed to relate the physical variables, such as altimetry, slope and soil type with the coffee agrosystems in Londrina-PR, through image by the Thematic Mapper sensor (TM) Landsat-5, along with the techniques of geoprocessing. It was created a database with information from altimetry, slope and soil classes, and through the map algebra, it was conducted the crossing of this information with the localization of the coffee fields, which was obtained by the classifier digital Bhattacharya applied in the image. The image from the TM enabled the mapping of $79 \%$ of coffee fields, and noticed that $86 \%$ of these fields are in altitudes higher than $540 \mathrm{~m}$ and $50 \%$ are located over areas from 8 to $20 \%$ of slope. About the soil, it was observed that the $53 \%$ of the coffee crops are located in Eutroferric Red Nitosol. All these tasks were performed through the SPRING 4.3.3 software, which had been an adequate tool to obtain agriculture data from satellite images.
\end{abstract}

KEYWORDS: coffee, geomatic, environmental characterization.

\footnotetext{
${ }^{1}$ Estudante de Doutorado, Instituto Nacional de Pesquisas Espaciais (INPE), kleber@dsr.inpe.br.

${ }^{2}$ Prof. Dr., Departamento de Agronomia da Universidade Estadual de Londrina (UEL), emiglior@uel.br.

${ }^{3}$ Prof. Dr., Departamento de Geociências da Universidade Estadual de Londrina (UEL), defranca@uel.br.

${ }^{4}$ Prof. Dr., Departamento de Geociências da Universidade Estadual de Londrina (UEL), coelho@uel.br.

Recebido pelo Conselho Editorial em: 1으-2-2010

Aprovado pelo Conselho Editorial em: 8-9-2010
} 


\section{INTRODUÇÃO}

A cultura do café sempre participou com uma grande parcela na economia brasileira, tanto no mercado interno, como nas exportações para o mercado internacional. No planejamento de políticas agrícolas, bem como nos sistemas de previsão de safras, informações da distribuição espacial e estimativa de área plantada são variáveis importantes na tomada de decisão por parte de especialistas que atuam nesta área.

A cafeicultura é a base econômica de vários municípios brasileiros. Nas décadas de 70 e 80 do século passado, Londrina foi considerada a capital mundial do café. Porém, devido às frequentes ocorrências de geadas no Estado, principalmente a geada de 1975, que dizimou diversas lavouras, fez com que a cultura migrasse para outras unidades da federação, como os Estados de Minas Gerais, Bahia, etc., onde o risco desse efeito episódico é bem menor. Atualmente, a área estimada com a cultura no município de Londrina é de 5.103 ha, praticamente a metade dos 10.753 ha que existia na década de 80 (SEAB, 2008).

Para a maioria das culturas agrícolas, os levantamentos sobre área plantada e produção são realizados por meio de informações coletadas nos municípios por agentes técnicos e dados econômicos, como financiamentos, entrevistas com produtores, vendas de insumos e fertilizantes, entre outros, o que torna os resultados dos levantamentos com baixa confiabilidade (OLIVEIRA, 2003).

Segundo GRIGG (1996), o Sistema de Informação Geográfica (SIG) é uma ferramenta que apresenta um grande potencial de suporte à tomada de decisão, podendo auxiliar no levantamento de informações e posterior planejamento de uma região. Desta forma, dados do sensoriamento remoto, quando tratados através do geoprocessamento, tornam-se uma ferramenta imprescindível no planejamento e no estudo dos recursos naturais (ODUM \& ODUM, 2001).

Na opinião de IPPOLITI-RAMILO (1998), nos levantamentos de cobertura da terra, por meio de imagens de satélites, os SIGs são ferramentas de extrema importância, pois melhoram a objetividade e a precisão dos resultados desses levantamentos. Com isso, os SIGs vêm sendo cada vez mais aplicados em áreas agrícolas, para estimar áreas plantadas, com resultados bastante satisfatórios, como os constatados nos trabalhos de XAVIER et al. (2004) e CAMPOS et al. (2004).

Nesse contexto, essa pesquisa teve como objetivo relacionar o agrossistema cafeeiro no município de Londrina - PR, com três variáveis físicas do ambiente, altimetria, declividade e classes de solo, utilizando imagens do sensor Thematic Mapper (TM) a bordo do satélite Landsat-5 e técnicas de geoprocessamento.

\section{MATERIAL E MÉTODOS}

Esta pesquisa foi realizada no município de Londrina, localizado ao norte do Estado do

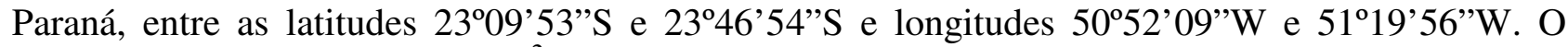
município, com área de $1.652 \mathrm{~km}^{2}$, situa-se no Terceiro Planalto paranaense, sobre a formação Serra Geral, que é essencialmente constituída por basaltos (rochas básicas), o que resulta, na maioria das vezes, na formação de solos argilosos. O relevo predominante na área é o suave ondulado (Figura 1).

O limite do município foi adquirido através do IBGE (2008), e o perímetro urbano de 2001, originado do Banco de Dados do IMAP\&P (Grupo Imagens, Paisagens e Personagens) da UEL/CNPq.

O clima da região é classificado conforme método de Köeppen como Cfa, ou seja, clima subtropical, com temperatura média no mês mais frio inferior a $18^{\circ} \mathrm{C}$ (mesotérmico), média anual de precipitação de $1.600 \mathrm{~mm}$, temperatura média no mês mais quente acima de $22^{\circ} \mathrm{C}$, com verões quentes, geadas pouco frequentes e tendência de concentração das chuvas nos meses de verão; contudo, sem estação seca definida. A vegetação é do tipo Floresta Estacional Semidecidual (IAPAR, 2000). 


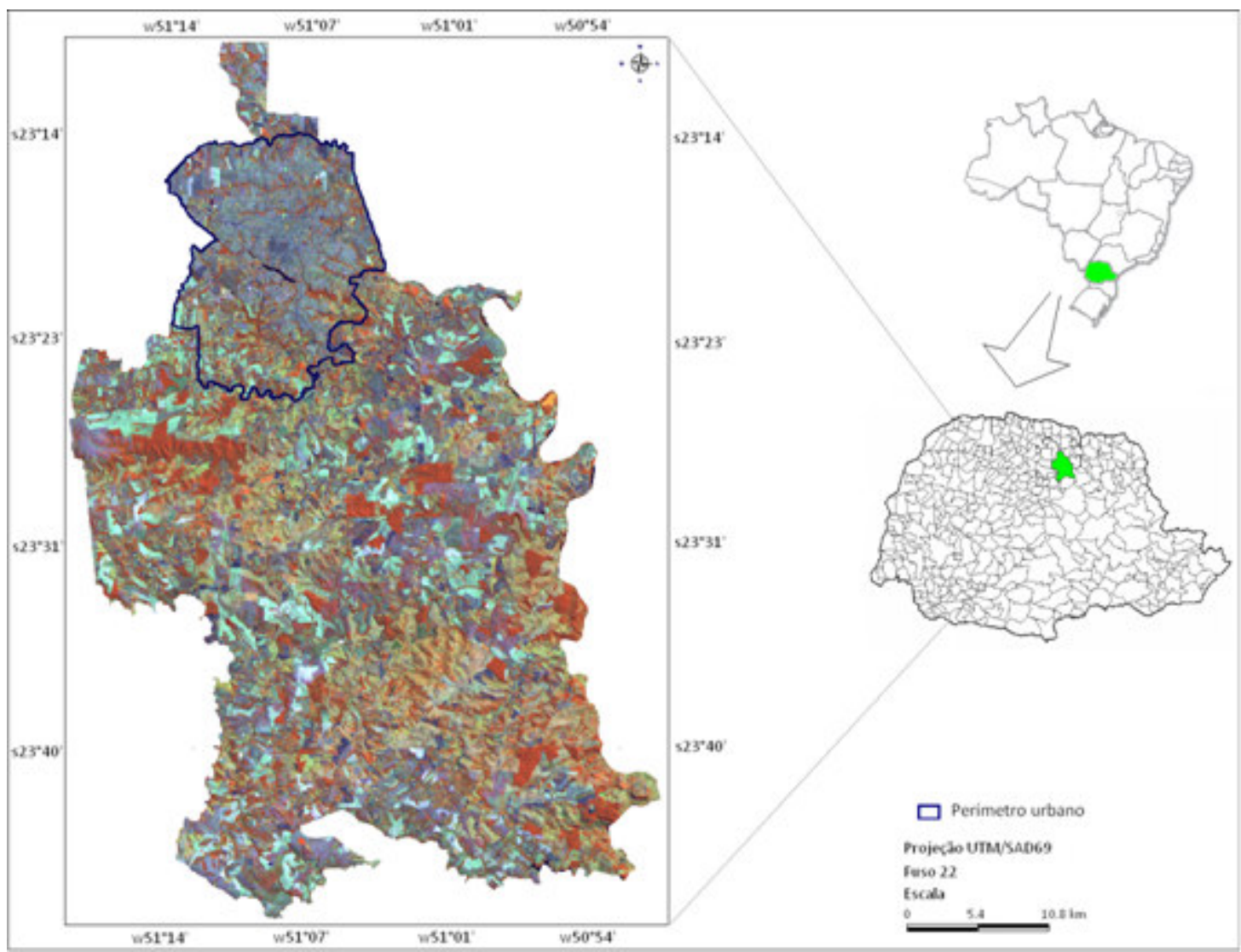

FIGURA 1. Localização do município de Londrina-PR, ilustrada com a imagem do sensor TM/Landsat-5, de 6-9-2007 na composição colorida R4G5B3. Localization of the city of Londrina-PR, illustrated with the image of the TM/Landsat-5 sensor, in 6/9/2007 in colorful composition R4G5B3.

Para caracterizar o agrossistema cafeeiro, empregou-se imagem do sensor TM do Landsat-5, da órbita/ponto 222/076; data da passagem de 6-9-2007, tratada no aplicativo SPRING 4.3.3, desenvolvido por pesquisadores do Instituto Nacional de Pesquisas Espaciais-INPE (INPE/DPI, 2004).

Foram realizados trabalhos de campo para levantar e georreferenciar amostras de lavouras de café, com o objetivo de estabelecer padrões espectrais para serem utilizados na interpretação da imagem de satélite e para avaliar a precisão dos resultados.

O mapeamento das lavouras de café nas imagens TM/Landsat-5 foi realizado através dos seguintes passos: i) georreferenciamento da imagem com oito pontos de controle, coletados a campo com GPS (Global Positioning System) de navegação Etrex; ii) restauração das bandas TM3, TM4 e TM5 realizada por um filtro linear, cujo objetivo é obter uma imagem realçada pela redução do efeito de borramento, além de corrigir distorções causadas pelos sensores, podendo-se gerar novas imagens com 15 m de resolução espacial (FONSECA, 1988); iii) seleção e ajuste de contraste linear das bandas resultantes da restauração; iv) segmentação por crescimento de regiões, realizada nas imagens das três bandas utilizadas. Para a segmentação, empregaram-se os valores de limiares de similaridade e área (pixels) de 11 e 17, respectivamente.

Esses valores foram obtidos por meio de vários testes até se chegar a um resultado satisfatório; v) classificação dos dados digitais através de uma abordagem supervisionada em que foi utilizado o classificador Bhattacharya (INPE/DPI, 2004); vi) para eliminar pixels isolados ou agrupados e pequenos números, utilizou-se a pós--classificação, a qual se resume em um filtro de média com uma matriz de 3x3, cujos limiar e peso foram de 1 , definidos após vários testes na imagem. 
Para finalizar, utilizando os resultados da classificação Bhattacharya, sobre uma imagem colorida TM4(R), TM5(G), TM3(B), foi feita a correção da classificação através de edição manual, na matriz, cuja função é denominada de Edição Matricial. Esta função, implementada no SPRING, permite que o analista interaja nos resultados da classificação para corrigir eventuais erros de omissão ou inclusão.

Para a análise da declividade e altimetria do terreno, elaborou-se uma carta de declividade e hipsometria; empregando curvas de nível equidistantes de $20 \mathrm{~m}$, originadas de dados da missão de radar Shuttle Radar Topography Mission (SRTM). Os dados do SRTM foram obtidos gratuitamente através do site http://seamless.usgs.gov, em grades de Modelos Numéricos do Terreno (MNT), com resolução de $90 \mathrm{~m}$.

O processamento da imagem SRTM foi todo realizado no recurso Modelo Numérico do Terreno (MNT), disponível no aplicativo SPRING. Foram determinadas as seguintes classes de declividade: plano: 0 a 3\%; suave ondulado: 3 a 8\%; ondulado: 8 a 20\%; forte ondulado: 20 a 45\%; montanhoso: > 45\% de declividade (LEMOS \& SANTO, 1984). Para obter o mapa hipsométrico, utilizaram-se cinco classes de altitude, estabelecidas por uma prévia avaliação das cotas mínima e máxima da área de estudo: Classe A: de 340 a 440 m; Classe B: de 440 a 540 m; Classe C: de 540 a 640 m; Classe D: 640 a 740 m e Classe E: 740 a 840 m.

Para caracterizar o solo no município, empregou-se o Levantamento de Reconhecimento dos Solos do Estado do Paraná (BRASIL, 1971), com escala aproximada de 1/300.000. O mapa foi escaneado e georreferenciado e, através desse mapa digital resultante, digitalizou-se o mapa de solos somente do município de Londrina, com cinco classes de solo, atualizadas segundo nomenclatura da EMBRAPA (1999): a) Latossolo Vermelho distroférrico (LVdf); b) Latossolo Vermelho eutroférrico (LVef); c) Nitossolo Vermelho distroférrico (NVdf); d) Nitossolo Vermelho eutroférrico (NVef), e e) Neossolo Litólico eutrófico (RLe).

Através de álgebra de mapas, fez-se o cruzamento do mapa temático de café com os mapas de declividade, hipsometria e classes de solos, por meio da Tabulação Cruzada disponível no SPRING. Tal ferramenta permitiu quantificar as áreas de café nas diferentes classes de declividade, altitude e solo.

\section{RESULTADOS E DISCUSSÃO}

Na Figura 2, é mostrado, sobre uma imagem colorida TM4(R), TM5(G) e TM3(B), o padrão espectral de duas áreas de café e de áreas de vegetação capoeira na região de estudo. Durante o mapeamento do café, observou-se que a vegetação capoeira, dependendo das condições de fitomassa, apresentou comportamento espectral semelhante ao comportamento espectral de algumas áreas de café, situação em que o classificador supervisionado Bhattacharya não conseguiu separar as lavouras cafeeiras desse tipo de vegetação, por causa da semelhança no padrão espectral, principalmente com as lavouras mais jovens, com baixo índice de área foliar (IAF), onde o solo tende a participar com maior intensidade na resposta espectral das lavouras. Esta constatação concorda com o trabalho realizado por DUARTE \& BRITO (2007), que observaram esta semelhança de comportamento espectral de áreas de café com cerrado.

Na Figura 3, pode ser visto o mapa temático com a localização e distribuição das áreas cafeeiras, obtidas através do classificador Bhattacharya. No município, a área de café foi de 4.055 ha. No entanto, a área mapeada com café pelo classificador Bhattacharya sem a edição matricial foi de 3.650 ha, ou seja, um erro de omissão de $11 \%$.

Para MOREIRA (2004), é fundamental que o resultado da classificação digital seja corrigido por meio da fotointerpretação na tela do computador, para eliminar os erros de classificação, principalmente. Segundo o autor, erros de omissão podem ocorrer devido aos diferentes padrões espectrais das lavouras. 


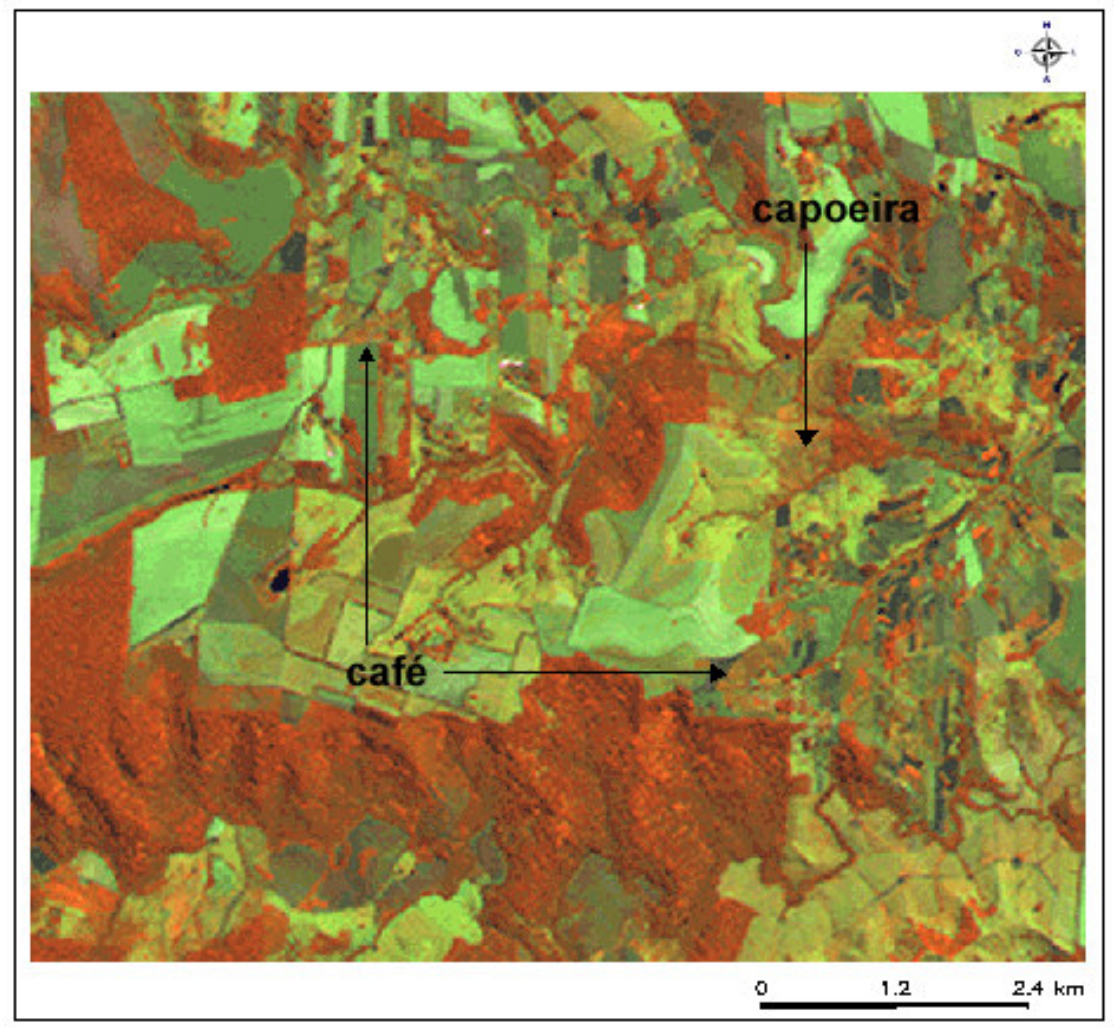

FIGURA 2. Imagem do satélite Landsat-5/TM em composição colorida RGB, na sequência TM4, TM5, TM3, restaurada e com realce, destacando-se lavouras de café e vegetação de capoeira, no município de Londrina-PR. Image of the satellite Landsat-5/TM, in colorful composition RGB, in the sequence TM4, TM5, TM3, restored and enhanced, detaching the coffee fields and secondary forest in Londrina-PR.

Segundo levantamentos da SEAB (Secretaria de Estado da Agricultura e Abastecimento) e do IBGE (Instituto Brasileiro de Geografia e Estatística), referentes à safra de 2006/2007, o município de Londrina possui uma área de aproximadamente 5.103 ha de café, o que lhe confere o $2^{\underline{o}}$ lugar no ranking estadual, em se tratando de área cultivada, ficando atrás somente de Carlópolis, com 6.038 ha (SEAB, 2008). Se comparados os resultados de mapeamento, os dados da atual pesquisa representam $79 \%$ do agrossistema cafeeiro quando relacionados aos dados governamentais oficiais, como os da SEAB, que utiliza censos agropecuários e entrevistas a campo para estimar a área cultivada. No entanto, é preciso estar ciente de que as fontes de informações oficiais e a desta pesquisa adotam metodologias diferentes para o levantamento da área. Enquanto as estatísticas oficiais são fortemente fundamentadas na coleta de dados a campo, na presente metodologia, o mapeamento da área é fundamentado em interpretação de imagem, o que pode fornecer resultados mais objetivos, quando comparado às estatísticas oficiais.

O tamanho médio das lavouras mapeadas nesta pesquisa foi de 9,5 ha, o que contradiz os resultados encontrados por MIGLIORANZA et al. (2007), ao afirmarem que, neste município, os cafezais apresentam área média de 7 ha. Na Figura 3, pode-se verificar que as lavouras cafeeiras são cultivadas muitas vezes em áreas de pequeno porte, com exceção de algumas propriedades de médio porte, vindo a dificultar na identificação e mapeamento da cultura, visto que a resolução espacial teórica da imagem Landsat-5/TM é de $30 \mathrm{~m}$, ou seja, $900 \mathrm{~m}^{2}$. Porém, com a restauração da imagem, obteve-se uma imagem com resolução espacial de $15 \mathrm{~m}$, ou seja, $225 \mathrm{~m}^{2}$ de pixel, auxiliando na classificação nas propriedades de pequeno porte. 


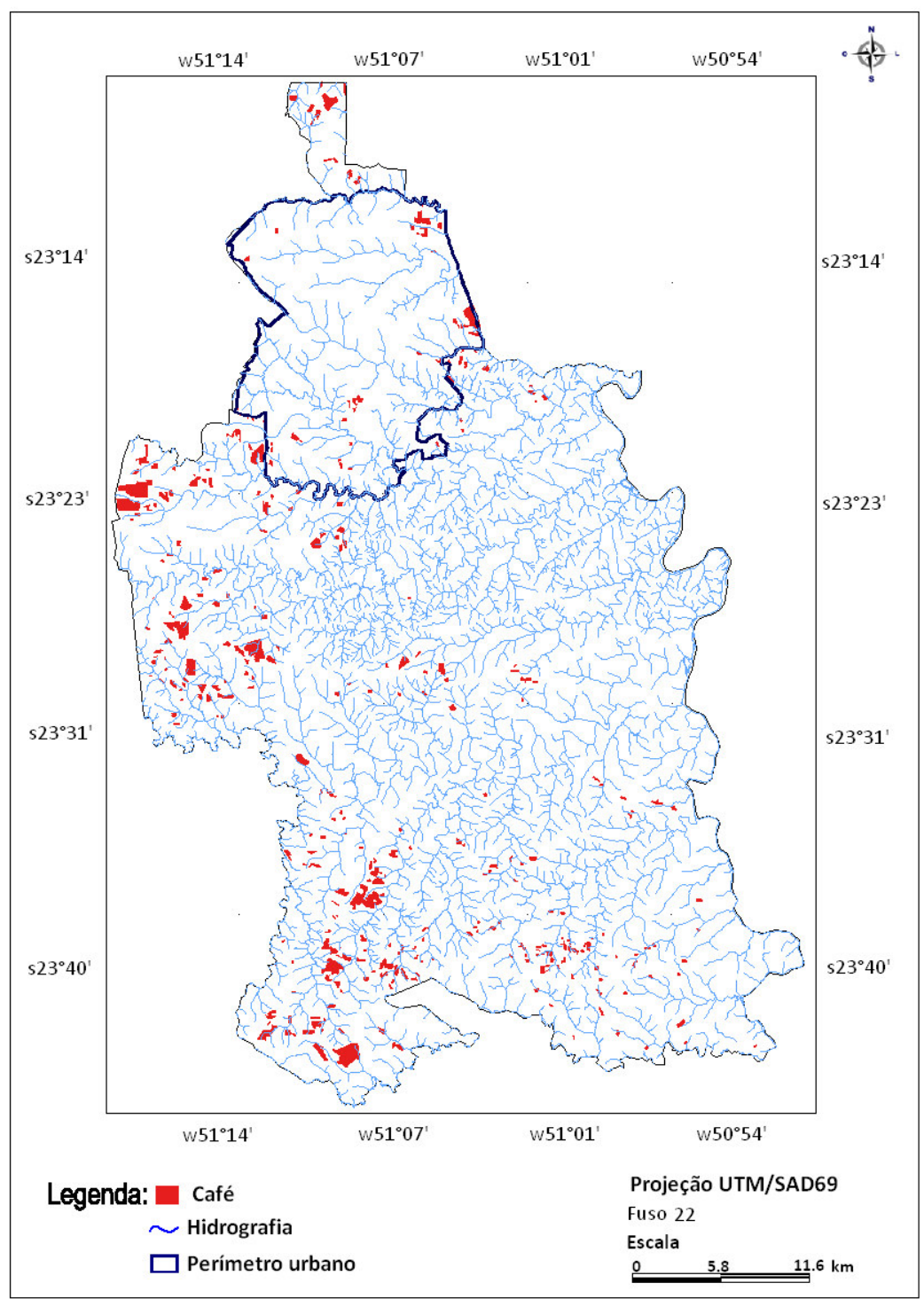

FIGURA 3. Mapa de localização e distribuição das lavouras cafeeiras do município de LondrinaPR, gerado após classificação de Bhattacharya e edição manual a partir da imagem Landsat-5/TM. Map of localization and distribution of the coffee fields in Londrina-PR generated after the Bhattacharya classification and manual edition from the Landsat-5/TM image.

Verificou-se também uma grande variabilidade espectral das lavouras, pois existem propriedades em que a lavoura ainda é manejada através do sistema tradicional, onde os espaçamentos mais antigos deixam o solo mais exposto, contribuindo para uma mistura de resposta espectral, como demonstrado na Figura 2. Segundo MOREIRA et al. (2004), lavouras plantadas no sistema tradicional, com 3 m entre linhas e 1,5 entre plantas, apresentam um padrão espectral muito influenciado pelo componente solo; já nas plantadas no sistema adensado, essa influência é menor. Fatores como espaçamento, idade, cultivar, face do relevo e tratos culturais podem influenciar no comportamento espectral das lavouras de café.

A partir da grade triangular (TINs), gerada pelas curvas de nível equidistantes de 20 metros, obteve-se o mapa hipsométrico do município de Londrina-PR. Neste mapa, verificou que a menor altitude no município foi de 340 metros, e a maior, de 840 metros. Na Figura 4, está contido o mapa hipsométrico com as cinco classes de altitude. 


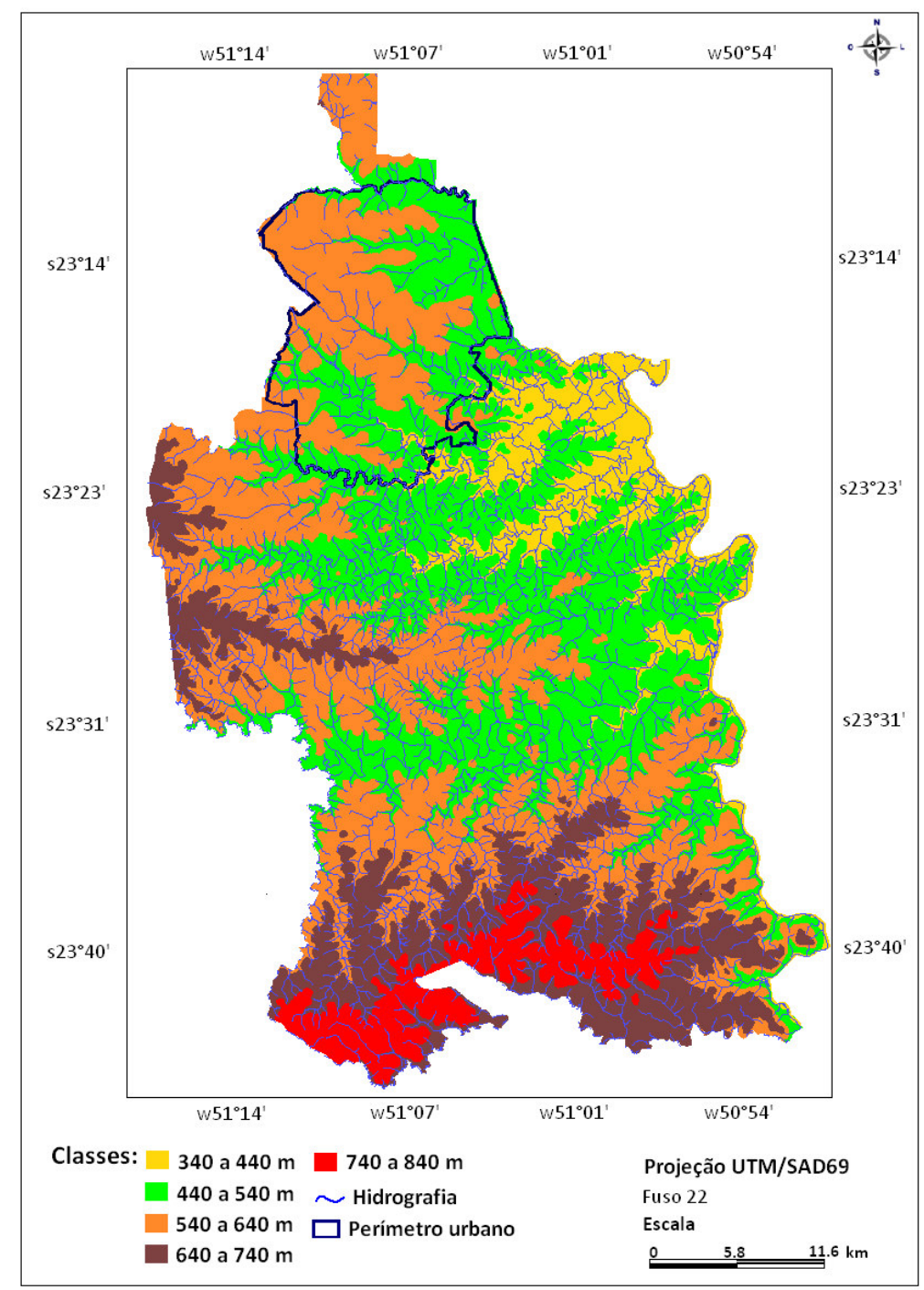

FIGURA 4. Mapa Hipsométrico do município de Londrina-PR, gerado a partir de dados SRTM. Hypsometric map of Londrina-PR generated from SRTM data.

Os resultados mostram que as classes com altitudes de 440 a $540 \mathrm{~m}$ e de 540 a $640 \mathrm{~m}$ predominam na área do município e representam um total de 58.972 ha e 55.725 ha, 36\% e 34\%, respectivamente (Tabela 1). No cruzamento do mapa de altitude com o mapa espacial das lavouras de café, verificou-se que cerca de $86 \%$ destas lavouras estão localizadas em altitudes superiores a 540 metros, sendo que a classe com altitude de 640 a $740 \mathrm{~m}$ possui $41 \%$ dos cafezais instalados no município. A classe de altitude com 540 a 640 m contém $34 \%$ dos cafezais. Para as classes de 440 a $540 \mathrm{~m}$ e 740 a $840 \mathrm{~m}$, foram encontradas $12 \%$ em cada classe de altitude, e o intervalo de 340 a 440 $\mathrm{m}$ foi encontrado em uma pequena parcela de $0,3 \%$ (Tabela 1 ).

Ao analisar os resultados contidos na Tabela 1, pode-se afirmar que 13,3\% das lavouras de café estão plantadas aquém da altitude recomendada. No Brasil, geralmente, o cafeeiro vem sendo cultivado em regiões com altitudes que variam de 400 a $1.200 \mathrm{~m}$ (MATIELLO et al., 2005). Segundo Sediyama et al. (2001), o plantio desta cultura não é recomendado para altitudes inferiores a $500 \mathrm{~m}$ e superiores a $1.200 \mathrm{~m}$.

Segundo CAMARGO (1998), as fases fenológicas do cafeeiro são bem definidas; porém, em regiões de maior altitude, a planta de café leva maior tempo para completar o ciclo reprodutivo. A influência da altitude no ciclo reprodutivo do cafeeiro está relacionada, principalmente, às temperaturas mais amenas em maiores altitudes. Para MALAVOLTA (2000), a altitude é um dos fatores que afetam a qualidade da bebida, sendo que o café cultivado em maiores altitudes amadurece mais lentamente, o que poderá resultar numa bebida de melhor qualidade. 
TABELA 1. Quantificação das classes de altitude no município de Londrina - PR, e localização de lavouras cafeeiras segundo as classes de altitude. Quantification of the altitude classes in Londrina - PR and localization of the coffee fields according to altitude classes.

\begin{tabular}{ccccc}
\hline Classes de Altitude & \multicolumn{2}{c}{ Londrina } & \multicolumn{2}{c}{ Lavoura Cafeeira } \\
\hline$(\mathrm{m})$ & Área (ha) & $\%$ & Área (ha) & $\%$ \\
\hline $340-440$ & 14.878 & 9,0 & 12 & 0,3 \\
$440-540$ & 58.972 & 36,0 & 520 & 13,0 \\
$540-640$ & 55.725 & 34,0 & 1.374 & 34,0 \\
$640-740$ & 26.439 & 16,0 & 1.659 & 41,0 \\
$740-840$ & 9.256 & 5,0 & 490 & 11,7 \\
\hline Total & 165.270 & 100 & 4.055 & 100 \\
\hline
\end{tabular}

Em relaçao à declividade, foi observado que, em Londrina-PR, $48 \%$ das terras apresentam declividade entre 8 a $20 \%$, declividade de 0 a $3 \%$, representa $30 \%$ da área. Já as classes de menor expressão, 3 a 8\%, 20 a $45 \%$ e maior que $45 \%$, apresentam, respectivamente, $14 \%, 8 \%$ e $0,4 \%$ da área (Figura 5 e Tabela 2).

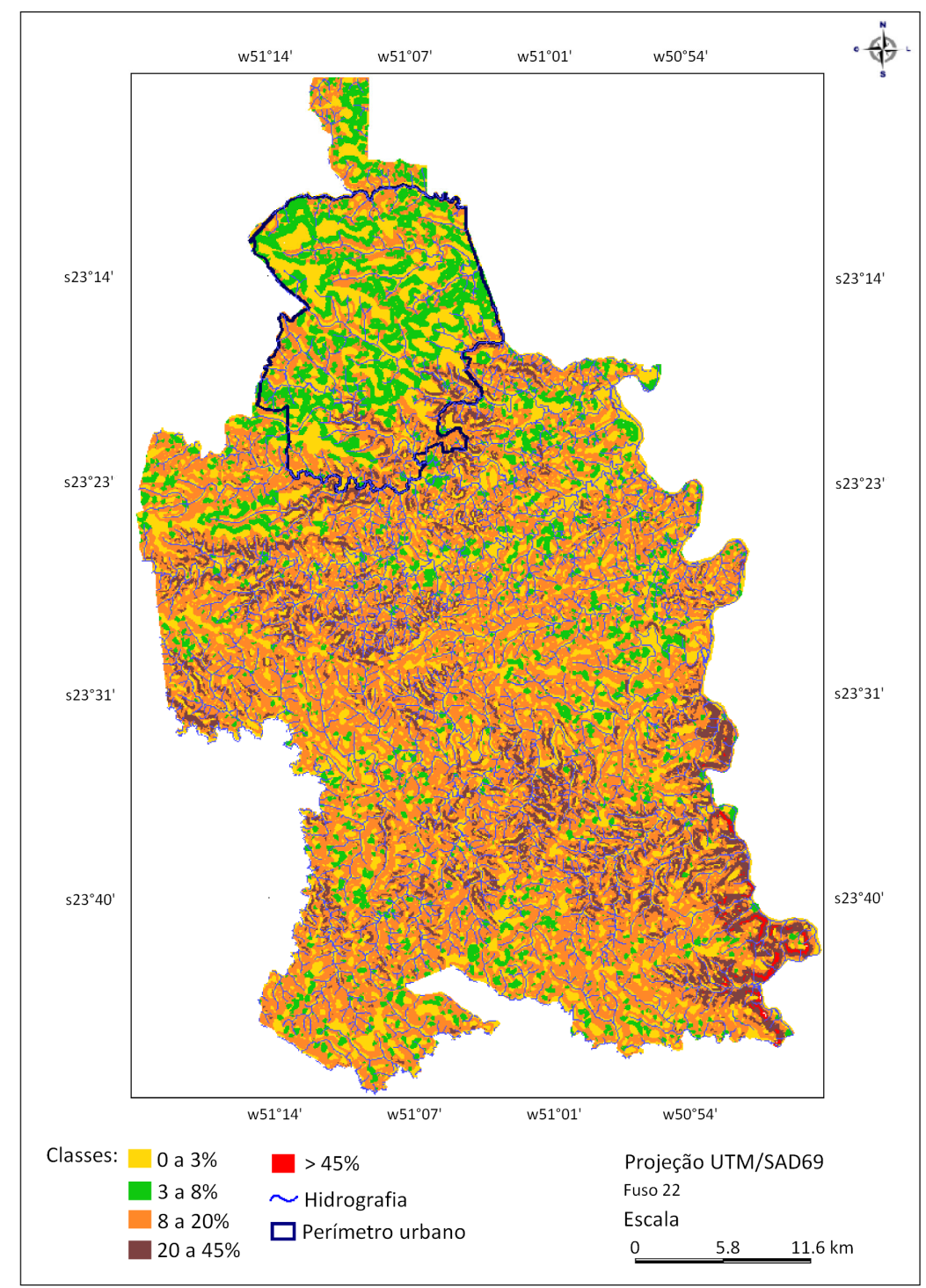

FIGURA 5. Mapa de Declividade do município de Londrina-PR, gerado a partir de dados SRTM. Declivity Map of Londrina-PR generated from SRTM data. 
A declividade determina o uso ou não de máquinas agrícolas, influencia no escoamento ou acumulação do ar frio e na velocidade de perda de solo pela erosão, e de modo geral, terrenos ondulados possuem solos com características melhores, pois a drenagem se faz de modo suficiente, e o processo erosivo pode ser reduzido, além de favorecer o escoamento do ar frio pelas encostas, diminuindo os riscos com as geadas (MATIELO et al., 2005).

$\mathrm{Na}$ região de estudo, foi observado que $50 \%$ das lavouras cafeeiras (2.024 ha) estão localizadas sobre terrenos com declividade de 8 a $20 \%$. Com declividade entre 0 a $8 \%$, foi observado $41 \%$ (1.824 ha), e cerca de 5\% das lavouras (207 ha) estão em terrenos com declividade acima de $20 \%$ (Tabela 2).

Assim, pode-se afirmar que as lavouras cafeeiras de Londrina-PR, estão em sua grande maioria localizadas em regiões adequadas quanto à declividade, favorecendo o manejo e as práticas mecanizáveis desde o plantio até a colheita.

TABELA 2. Quantificação das classes de declividade no município de Londrina-PR, e localização das lavouras cafeeiras segundo as classes de relevo. Quantification of the slope classes in Londrina-PR and localization of the coffee fields according to relief classes.

\begin{tabular}{|c|c|c|c|c|c|}
\hline \multicolumn{2}{|c|}{ Classes de Declividade } & \multicolumn{2}{|c|}{ Londrina } & \multicolumn{2}{|c|}{ Lavoura Cafeeira } \\
\hline Classes & Declive & Área (ha) & $\%$ & Área (ha) & $\%$ \\
\hline Plano & 0 a $3 \%$ & 49.536 & $\overline{30,0}$ & 1.233 & 31,0 \\
\hline Suave ondulado & 3 a $8 \%$ & 22.056 & 14,0 & 591 & 14,0 \\
\hline Ondulado & 8 a $20 \%$ & 78.749 & 48,0 & 2.024 & 50,0 \\
\hline Forte ondulado & 20 a $45 \%$ & 14.535 & 8,0 & 207 & 5,0 \\
\hline Montanhoso & $>45 \%$ & 390 & 0,4 & 0 & 0,0 \\
\hline \multicolumn{2}{|c|}{ Total } & 165.270 & 100 & 4.055 & 100 \\
\hline
\end{tabular}

Na Figura 6, mostra-se a distribuição espacial das cinco classes de solo no município, e a Tabela 3 contém a área da classe de solo no município e a sua relação com as lavouras de café.

Ao observar a distribuição espacial das cinco classes de solo no município, nota-se que o Nitossolo Vermelho eutroférrico (NVef) é o predominante. Os resultados contidos na Tabela 3 mostram a seguinte distribuição: NVef (54\%); RLe (26\%); LVdf (10\%); LVef (8\%) e o NVdf (2\%).

Com relação às lavouras cafeeiras e a classe de solo, os resultados contidos na Tabela 3 mostram uma predominância de lavouras de café na classe NVef (53\%). Essa predominância, de certa forma, é esperada, uma vez que essa classe de solo é predominante no município. Além disso, essa classe de solo apresenta alta disponibilidade de nutrientes, devido à soma de bases elevadas (> $50 \%$ ) e aos teores de óxido de ferro elevado $\left(\mathrm{Fe}_{2} \mathrm{O}_{3}\right)$, de 15 a $36 \%$, o qual auxilia na fixação do elemento fósforo, favorecendo a cultura instalada.

Para as demais classes, o percentual de cafezais por classe de solo é a seguinte: na classe LVef (19,3\%); em LVdf existe 14\% ocupado com café; $13 \%$ das lavouras do município RLe e apenas $0,7 \%$ das lavouras estão localizadas sobre a classe NVdf. 


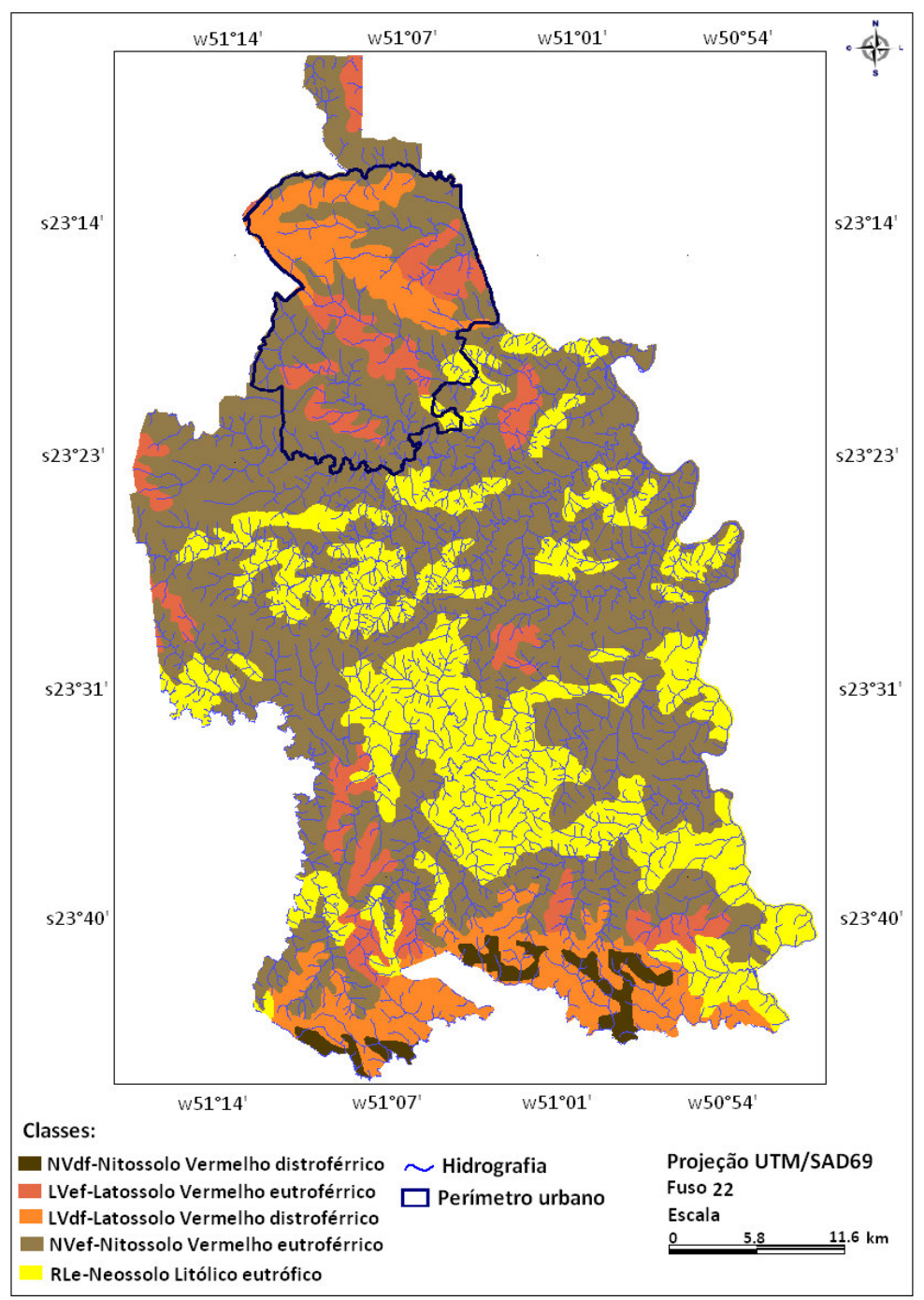

FIGURA 6. Mapa de Solos do município de Londrina-PR, gerado a partir do Levantamento de Reconhecimento dos Solos do Estado do Paraná (1971). The Soil Map of LondrinaPR, generated from the Recognition Survey of the Soils of the State of the Parana (1971).

TABELA 3. Quantificação das classes de solos no município de Londrina-PR, e localização das lavouras cafeeiras segundo as classes de solo. Quantification of the soil classes of Londrina-PR and localization of the coffee fields according to the soil classes.

\begin{tabular}{lrrrr}
\hline \multicolumn{1}{c}{ Classes de Solo } & \multicolumn{2}{c}{ Londrina } & \multicolumn{2}{c}{ Lavoura Cafeeira } \\
\hline Solo & ha & $\%$ & ha & $\%$ \\
\hline LVef - Latossolo Vermelho eutroférrico & 12.780 & 8,0 & 792 & 19,3 \\
NVef - Nitossolo Vermelho eutroférrico & 89.658 & 54,0 & 2.158 & 53,0 \\
LVdf - Latossolo Vermelho distroférrico & 16.874 & 10,0 & 583 & 14,0 \\
RLe - Neossolo Litólico eutrófico & 42.944 & 26,0 & 494 & 13,0 \\
NVdf - Nitossolo Vermelho distroférrico & 3.001 & 2,0 & 28 & 0,7 \\
\hline Total & 165.270 & 100 & 4.055 & 100 \\
\hline
\end{tabular}

Por outro lado, as lavouras que ocorrem sobre a classe Neossolo Litólico eutrófico (RLe) requerem um criterioso manejo agrícola sob o aspecto conservacionista, uma vez que esta classe se caracteriza por solos rasos e pouco desenvolvidos, encontrados normalmente em relevo forte ondulado; por conseguinte, possuem alta vulnerabilidade a processos erosivos. Já os solos da classe Latossolo Vermelho (LV) são profundos, bem drenados, geralmente encontrados em relevo suave 
ondulado e originário de rochas básicas, o que os caracteriza como mecanizáveis e favoráveis à prática agrícola (RESCKet al., 1991).

\section{CONCLUSÕES}

A metodologia adotada para mapear as lavouras de café, através de imagens do TM do Landsat-5, classificação supervisionada, com posterior edição matricial mostrou-se eficiente.

Mais de $50 \%$ das lavouras cafeeiras estão localizadas em solos que favorecem o seu crescimento e desenvolvimento.

Quanto à declividade, 50\% destas lavouras encontram-se em declividade favorável ao cultivo desta cultura.

Aproximadamente $75 \%$ dos cafeeiros estão localizados entre altitudes de 540 e 740 m, o que se enquadra nas exigências da cultura, segundo a literatura.

Assim, o município de Londrina - PR apresenta regiões fisiográficas aptas ao cultivo do café, quando considerados os aspectos de declividade, altitude e solos.

\section{AGRADECIMENTOS}

À CAPES, pela concessão da bolsa de estudos durante a realização deste trabalho.

\section{REFERÊNCIAS}

BRASIL. Ministério da Agricultura. Departamento Nacional de Pesquisa Agropecuária.

Levantamento de reconhecimento dos solos do Nordeste do Estado do Paraná. Curitiba, 1971. 144 p. (Boletim Técnico, 16).

CAMARGO, A.P. As oito fases fenológicas da frutificação do cafeeiro. In: CONGRESSO BRASILEIRO DE PESQUISAS CAFEEIRAS, 24., 1998, Poços de Caldas. Anais... Rio de Janeiro: Instituto Brasileiro do Café, 1998. p.41-42.

CAMPOS, S.; SILVA, M.; PIROLI, L.; CARDOSO, L.G.; BARROS, Z.X. Evolução do uso da terra entre 1996 e 1999 no município de Botucatu-SP. Engenharia Agrícola, Jaboticabal, v.24, n.1, p 211-218, 2004.

DUARTE, W.O.; BRITO, J.L.S. Mapeamento da Cultura do Café no município de Araguari-MG, utilizando imagens do sensor CCD do satélite CBERS-2. In: SIMPÓSIO BRASILEIRO DE SENSORIAMENTO REMOTO, 13., 2007, Florianópolis. Anais... São José dos Campos: INPE, 2007. p.161-167.

EMBRAPA. EMPRESA BRASILEIRA DE PESQUISA AGROPECUÁRIA. Sistema brasileiro de classificação de solos. Rio de Janeiro: Centro Nacional de Pesquisa de Solos, 1999.

FONSECA, L.M.G. Restauração e interpolação de imagens do satélite Landsat por meio de técnicas de projeto de filtros FIR. 1998. 148 f. Dissertação (Mestrado em Engenharia Elétrica) Instituto Tecnológico da Aeronáutica, São José dos Campos, 1998.

GRIGG, N.S. Water resources management: principles, regulations, and cases. New York: McGraw-Hill Book, 1996.

IAPAR. INSTITUTO AGRONÔMICO DO PARANÁ. Cartas climáticas do Estado do Paraná. Londrina, 2000. p.9-11.

IBGE. INSTITUTO BRASILEIRO DE GEOGRAFIA E ESTATÍSTICA. Produção agrícola municipal 2006. Brasília. Disponível em: <http://www.sidra.ibge.gov.br/. Acesso em: 2 abr. 2008. 
IBGE. INSTITUTO BRASILEIRO DE GEOGRAFIA E ESTATÍSTICA. Malhas digitais 2007. Brasília. Disponível em <ftp://geoftp.ibge.gov.br/mapas/malhas_digitais/>. Acesso em: 28 mar. 2008.

INPE/DPI. INSTITUTO NACIONAL SISTEMA DE PROCESSAMENTO DE INFORMAÇÕES GEORREFERENCIADAS (SPRING 4.3.3), 2004. Disponível em: <http://www.inpe.br/spring > Acesso em: 10 abr. 2008.

IPPOTILI-RAMILO, G.A. Imagens TM/Landsat-5 da época de pré-plantio para a previsão da área de culturas de verão. 1998. 183 f. Dissertação (Mestrado em Sensoriamento Remoto) - Instituto Nacional de Pesquisas Espaciais, São José dos Campos, 1998.

LEMOS, R.C.; SANTOS, R.D. Manual de descrição e coleta de solo no campo. Campinas: Sociedade Brasileira de Ciência do Solo e Serviço Nacional de Levantamento e Conservação de Solos, 1984. 45 p.

MALAVOLTA, E. História do café no Brasil: agronomia, agricultura e comercialização. São Paulo: Agronômica Ceres, 2000. 464 p.

MATIELLO, J.B.; SANTIAGO, R.; GARCIA, A.W.R.; ALMEIDA, S.R.; FERNANDES, D.R. Cultura de café no Brasil: novo manual de recomendações. Rio de Janeiro: Varginha, MAPA /PROCAFE, 2005. 387 p.

MIGLIORANZA, R.; MASSARUTTI, J.; MIGLIORANZA, E. Perfil dos produtores de café orgânico e de café tradicional no município de Londrina. 2007. In: SIMPÓSIO DE PESQUISAS DOS CAFÉS DO BRASIL, 5., 2007, Águas de Lindóia. Anais... Brasília: EMBRAPA CAFÉ, 2007. p.1-5.

MOREIRA, M.A.; ADAMI, M.; RUDORFF, B.F.T. Análise espectral e temporal da cultura do café em imagens Landsat. Pesquisa Agropecuária Brasileira, Brasília, v.39, p.223-231, 2004.

NASA. NATIONAL AERONAUTICS AND SPACE ADMINISTRATION. United States Geological Survey -USGS). Shuttle radar topography mission data (SRTM). Sioux Falls: USGS, 2000. Disponível em: <http://seamless.usgs.gov/website/seamless/viewer.php>. Acesso em: 21 nov. 2008.

ODUM, H.T.; ODUM, E.C. A prosperous way down: principles and policies. Colorado: University Press of Colorado, 2001.

OLIVEIRA, J.C. Índice para avaliação de segmentação (IAVAS): uma aplicação em agricultura. 2003. 160 f. Dissertação (Mestrado em Sensoriamento Remoto) - Instituto Nacional de Pesquisas Espaciais, São José dos Campos, 2003.

RESCK, D.V.S.; PEREIRA, J.; SILVA, J.E. Dinâmica da matéria orgânica na região dos cerrados. Planaltina: Embrapa-CPAC, 1991. 22 p. (Documentos, 36).

SEAB. SECRETARIA DE ESTADO DA AGRICULTURA E ABASTECIMENTO. Safra 2006/2007. Disponível em: <http://www.seab.pr.gov.br/arquivos/File/PDF/SAFRA_2006.pdf>. Acesso em: 26 fev. 2008.

SEDIYAMA, G.C.; JUNIOR, J.C.F.M.; SANTOS, A.R.; RIBEIRO, A.; COSTA, M.H.; HAMAKAWA, P.J.; COSTA, J.M.N.; COSTA, L.C. Zoneamento agroclimático do cafeeiro (Coffea arábica L.) para o Estado de Minas Gerais. Revista Brasileira de Agrometeorologia, v.9, n.3, p.501-509, 2001.

XAVIER, A.C.; VETTORAZZI, C.A.; MACHADO, R.E. Relação entre índice de área foliar e frações de componentes puros do modelo linear de mistura espectral, usando imagens ETM+/Landsat. Engenharia. Agrícola, Jaboticabal, v.24, n.2, p.421-430, 2004. 